\title{
Erratum to: The current landscape of television and movies in medical education
}

\author{
Marcus Law · Wilson Kwong · Farah Friesen · \\ Paula Veinot $\cdot$ Stella $\mathrm{L}$. Ng
}

Published online: 30 November 2015

(C) The Author(s) 2015. This article is published with open access at Springerlink.com

Erratum to: Law et al. "The current landscape of television and movies in medical education". Perspect Med Educ (2015) 4(5):218-224 DOI 10.1007/s40037-015-0205-9

Page 221, left column, under the section "Topics/Content (What?)": Owing to an unfortunate oversight, the last sen-

The online version of the original article can be found under doi:10.1007/s40037-015-0205-9

Electronic supplementary material The online version of this article (doi: 10.1007/s40037-015-0235-3) contains supplementary material, which is available to authorized users.

M. Law $(\bowtie)$

Department of Family \& Community Medicine,

Faculty of Medicine, University of Toronto;

Centre for Faculty Development, Li Ka Shing Knowledge

Institute, Toronto; and Toronto East General Hospital,

Room 2325, Medical Sciences Building, 1 King's College Circle,

M5S 1A8 Toronto, ON, Canada

e-mail:marcus.law@utoronto.ca

W. Kwong

Queen's University,

Kingston, ON, Canada

F. Friesen

Centre for Faculty Development,

Li Ka Shing Knowledge Institute,

Toronto, ON, Canada

P. Veinot $\cdot$ S.L. Ng

Centre for Faculty Development, Li Ka Shing Knowledge Institute, Toronto; Department of Speech-Language Pathology,

University of Toronto; Centre for Ambulatory Care Education,

Women's College Hospital,

Toronto, ON, Canada tence of this section was truncated during proof correction. The sentence should read: "For details about each study, please refer to the Electronic Supplementary Material".

An extended version of the table in the Electronic Supplementary Material is available with this erratum.

Open Access This article is distributed under the terms of the Creative Commons Attribution License which permits any use, distribution, and reproduction in any medium, provided the original author(s) and the source are credited.

Marcus Law, MD, MBA, MEd is Director of Preclerkship Renewal \& Academic Innovation Undergraduate Medical Education, at the University of Toronto.

Wilson Kwong, MSc is a final year medical student at Queen's University.

Farah Friesen, MI is research coordinator at the Centre for Faculty Development, University of Toronto.

Paula Veinot, MHSc is an independent research consultant.

Stella L. Ng, PhD is Director of Research at the Centre for Faculty Development, University of Toronto. 